\title{
GLOBALIZAÇÃO, TRABALHO E FORMAÇÃO HUMANA: NOTAS PARA A PROBLEMATIZAÇÃO DA EDUCAÇÃO ESCOLAR
}

\author{
Celso João Ferretti \\ Fernando Casadei Salles \\ Jorge Luis Cammarano González ${ }^{\text {i }}$
}

\begin{abstract}
RESUMO:
Este escrito examina as relações entre globalização, trabalho e formação humana centrando sua atenção na compreensão das mudanças em curso no capitalismo e suas mediações com os processos constitutivos das práticas escolares formativas do indivíduo. Parte-se do entendimento da Instituição Escolar como instituição social: (a) produto e produtora dos conflitos e antagonismos subjacentes às práticas sociais centradas na relação Capital Trabalho Assalariado - Propriedade Privada; (b) que se objetiva nas múltiplas mediações entre Sociedade e Estado; (c) cuja investigação deve relevar sua objetividade social posta historicamente no contexto das formas e dos tempos da sociedade capitalista e (d) que materializa uma das múltiplas dimensões da reprodução social, com práticas formativas específicas em seus diversos níveis, cotidianamente realizadas por meio de processos de gestão, ensino, avaliação, em suma, das políticas educacionais e da produção específica da cultura escolar. Ponderamos que o complexo social educação, objetiva a constituição do sujeito em determinado momento histórico, por isso, há que se estudar como se organiza tal complexo, mas também, qual é a racionalidade do processo de socialização que dá o curso do movimento desse complexo e de suas mediações com a totalidade dos complexos sociais. Em outros termos, entendida em seu significado mais amplo, a educação busca constituir o sujeito para o momento histórico em curso. Partimos do suposto de que tal enfoque contribuiria para pôr em debate o que se tem proposto para a educação nos seus mais diversos matizes e para a ampliação do entendimento que se tem das complexas relações entre trabalho, formação humana e educação escolar com suas derivações nos processos de produção/apropriação de conhecimento e de institucionalização das práticas formativas.
\end{abstract}

Palavras-chave: Trabalho, Formação Humana, Educação Escolar, Globalização.

\section{GLOBALIZATION, WORK AND HUMAN FORMATION: NOTES TO THE QUESTIONING OF THE SCHOOLING EDUCATION}

\begin{abstract}
:
This writing examines the relations among globalization, work and human formation pointing their attention to the comprehension of the changes in progress into the capitalism and its mediations by the processes constituted from the teaching school practices that form the individual. The School Institution is understood as a social institution: (a) which is a product and a generator of conflicts and antagonisms beneath the social practices centered on the relation Capital - Waged Work - Private Property; (b) which has the purpose the multiple mediations between Society and State; (c) of which investigation must emphasize its social objectivity that is set historically in the context of the patterns and periods of the capitalist society and (d) which materializes one of the multiple dimensions of the social reproduction with specific practices that form the individual in
\end{abstract}


their several levels accomplished everyday through the processes of management, teaching, evaluation. In short, the ones accomplished through educational politics and through a specific production of the schooling culture. We think the social complex education has the purpose the individual formation in a certain historical moment, therefore there is a need to study how it is organized such complex education as well as the question of which is the reasonableness of the socialization process that gives the way of the movement of this complex one and of its mediations in relation to the social complex educations. In other words, once is understood its larger meaning, the education seeks to constitute the individual for the current historical moment. We tend to assume that such point of view would contribute to the debate on what we have set out to the education in its several shades and to the enlargement of the understanding of the complex relations among work, human formation and schooling education with their bypass on the processes of production/appropriation of the knowledge and the institutionalization of the practices that form the individual.

Key-Words: Work; Human Formation; Schooling Education; Globalization

\section{Apresentação}

Este escrito examina as relações entre globalização, trabalho e formação humana centrando sua atenção na compreensão das mudanças em curso no capitalismo e suas mediações com os processos constitutivos da escola em suas práticas de formação do indivíduo.

Parte-se do entendimento da Instituição Escolar como instituição social: (a) produto e produtora dos conflitos e antagonismos subjacentes às práticas sociais centradas na relação Capital - Trabalho Assalariado - Propriedade Privada; (b) que se objetiva nas múltiplas mediações entre Sociedade e Estado; (c) cuja investigação deve relevar sua objetividade social posta historicamente no contexto das formas e dos tempos da sociedade capitalista e (d) que materializa uma das múltiplas dimensões da reprodução social, com práticas formativas específicas em seus diversos níveis, cotidianamente realizadas por meio de processos de gestão, ensino, avaliação, em suma, das políticas educacionais e da produção específica da cultura escolar. Observamos, complementarmente, que a Instituição escolar expressa relações e mediações da sociabilidade cotidiana produzida, reproduzida e tensionada por indivíduos, grupos e classes sociais, nos limites e possibilidades históricas da sociedade brasileira contemporânea.

Ponderamos que o complexo social educação objetiva a constituição do sujeito em determinado momento histórico, por isso, há que se estudar como se organiza tal complexo, mas também, qual é a racionalidade do processo de socialização que dá o curso do movimento desse complexo e de suas mediações com a totalidade dos complexos sociais. Em outros termos, entendida em seu significado mais amplo, a educação busca constituir o sujeito para o momento histórico em curso.

Partimos do suposto de que tal enfoque contribuiria para pôr em debate o que se tem proposto para a educação nos seus mais diversos matizes e para a ampliação do entendimento que se tem das complexas relações entre trabalho, formação humana e educação escolar com suas derivações nos processos de produção/apropriação de conhecimento e de institucionalização das práticas formativas.

Para analisar a educação formal e nela a formação do indivíduo, reafirma-se a necessidade de levar em conta alguns elementos teóricos. Antes de tudo é necessário conhecer-se o complexo social a partir de sua especificidade, no caso em tela, é necessário 
investigar a dinâmica da denominada globalização e explicitar minimamente duas categorias, a nosso ver centrais para a problematização em pauta, isto é, as categorias Trabalho e Formação.

\section{Sobre a Globalização}

Que aspectos da denominada globalização nos auxiliariam para o entendimento das práticas reformistas que se alastram desde os centros hegemônicos do Capital para os países periféricos visando estabelecer políticas para a formação dos indivíduos nos espaços escolares em atendimento às transformações no mundo do trabalho subsumido à lógica do Capital?

Uma possível resposta a essa indagação requer, a nosso ver, o registro de dados relativos ao contexto em que as reformas da sociedade em curso tendem a se materializar.

O mais recente informe da Organização das Nações Unidas para o Desenvolvimento (segundo reportagem de Le Monde de 10 de setembro de 1998) mostra que o consumo global de bens e serviços foi duas vezes maior em 1997 do que em 1975 e se multiplicou por seis desde 1950, mas que mesmo assim 1 bilhão de pessoas 'não podem satisfazer sequer suas necessidades básicas'. Sessenta por cento dos 4,5 bilhões de habitantes dos países 'em desenvolvimento' não tem acesso a infra-estruturas básicas: um terço não tem acesso a água potável, um quarto não tem moradia digna desse nome, um quinto não dispõe de serviços médicos e sanitários. Um quinto das crianças passa menos de cinco anos na escola e uma porção semelhante vive em permanente subnutrição. Em 70 a 80 dos cerca de 100 países em 'desenvolvimento', a renda média per capita é hoje inferior à de dez ou mesmo trinta anos atrás. Cerca de 120 milhões de pessoas vivem com menos de um dólar por dia.

Ao mesmo tempo, nos EUA, de longe o país mais rico do mundo e da terra natal do povo mais abastado do planeta, 16,5 por cento da população vive na pobreza, um quinto dos homens e mulheres adultos não sabe ler nem escrever e 13 por cento têm uma expectativa de menos de 60 anos de vida.

Por outro lado, os três homens mais ricos da terra têm uma riqueza privada maior que o produto nacional bruto somado dos 48 países mais pobres; e a fortuna das quinze pessoas mais ricas do mundo excede o produto total de toda a África subsaariana. Segundo o informe da ONU, menos de 4 por cento da riqueza pessoal das 225 pessoas mais ricas do globo bastaria para garantir a todos os pobres do mundo os serviços médicos e educacionais elementares, além de alimentação adequada (BAUMAN, 2000, p. 177).

A força desses dados precisa ser articulada a uma análise que transcenda as inevitáveis impressões e que busquem as possíveis causas dessas estatísticas que cotidianamente se revelam em extermínios dos mais variados matizes e assumem feições que transitam do suicídio às guerras inter e intranações. Buscar as raízes para além dos dados também significa a busca dos processos historicamente fundantes da lógica do Capital que se desdobra nas múltiplas dimensões citadas por Bauman (2000) tentando o discernimento e a contraposição aos processos de naturalização das relações sociais e de internalização de valores que preservam e buscam perpetuar os processos de dominação e exploração capitalista. É nesse contexto que a formação dos indivíduos no âmbito da educação escolar em todos seus níveis em atendimento às transformações no mundo do trabalho subsumido à lógica do Capital representa um campo de fundamental importância 
para a estratégia reformista posto que as mudanças dos processos produtivos demandam a mediação de práticas escolarizadas mobilizadas para a formação de um trabalhador de "novo tipo".

É dessa estratégia que a lógica do capital e seus manipuladores derivam parte da possibilidade de manter, aprofundar e alargar a desigualdade social, a precarização do trabalho e a conversão das múltiplas dimensões da vida em mercadoria.

$\mathrm{O}$ entendimento dos possíveis determinantes desse processo requer caracterizar, minimamente, seu contexto histórico. Nessa direção assinalamos como antecedentes desse contexto que, a partir de meados da década de 1980, inúmeras inovações científicas e tecnológicas, como a microeletrônica, a robótica, a química fina, a biotecnologia e a fibra ótica passam a ser incorporadas pelos processos produtivos do mundo capitalista demandando mudanças nos processos de qualificação da força de trabalho. Entretanto, essa descrição não incide em considerarmos tais mudanças como sujeitos desse processo, antes concebemos que essas transformações na base técnico-produtiva atendem aos esforços implementados pelo capital na perspectiva de controlar e subordinar o trabalho. Ponderamos que estas mudanças fomentariam, gradativamente, a superação de práticas fordistas de produção e a adoção de modelos produtivos mais flexíveis, que culminariam em algumas regiões do mundo capitalista, com uma racionalização da produção orientada pelo toyotismo.

Além das alterações nos setores produtivos, o mundo passaria a viver uma recomposição geopolítica no rastro da desestruturação do projeto socialista nos países do Leste Europeu. Essas transformações pautam-se pela intensificação das relações capitalistas de produção, configurando um processo que se desenvolve sob o comando dos grandes conglomerados transnacionais e seus agentes multilaterais - BIRD, BID, FMI e OMC. Nesse contexto o modelo político do Estado do Bem-Estar Social vai sendo gradativamente substituído pelo ideário pautado na política neoliberal. Essa política busca a ampliação de mercados, a desregulamentação das economias nacionais, a privatização e apropriação de serviços públicos pelos grandes capitais e a precarização do trabalho na perspectiva de ruptura com o contrato social resultante dos embates entre capital e trabalho, derivados do período pós Segunda Guerra Mundial e materializado nas políticas sociais de um Estado qualificado como Estado do bem-estar social. A dinâmica desses processos com seus tempos e formas específicas acaba por produzir, intermediadas pela ação dos organismos financeiros internacionais, interferências e ingerências nos campos político, cultural, social e econômico, que em parte se materializam na reforma do Estado e, especificamente, nas reformas consumadas no âmbito da educação escolar.

A política reformista assume feições planetárias, ou seja, são inúmeros os países submetidos à lógica de buscar alternativas que fomentem a permanência do capital como sistema hegemônico. O Brasil não foi exceção. A partir da década de 1990, sob a orientação do projeto político presidido por Fernando Henrique Cardoso, o país empreende uma reforma do Estado, - já iniciada por Fernando Collor de Mello -; e da educação, inspirada nesse contexto mundial, minimamente, mencionado anteriormente. Entretanto, deve-se observar que o Estado assume nova envergadura que se materializa na abertura da economia nacional ao capital externo; em amplo programa de privatização de sua infraestrutura; na flexibilização das leis trabalhistas; na Reforma da Previdência; na Lei de Responsabilidade Fiscal; traduzindo um conjunto de medidas que atendiam prontamente aos anseios dos grandes conglomerados transnacionais desejosos e necessitados de um mercado regulado da perspectiva do fortalecimento da lógica do capital. Em outros termos, a reforma do Estado brasileiro reflete a relação de conciliação e dependência que 
caracterizou historicamente a postura dos setores dominantes nacionais em relação aos setores dominantes internacionais.

O entendimento do contexto histórico que tem fomentado a produção da política reformista para a educação, resguarda-se em dois pressupostos. O primeiro, diz respeito ao entendimento da educação contemporânea como um fenômeno global. Ou seja, todo problema específico local ou regional de educação deve se refletir em um problema de extensão mundial, na medida em que, a educação, como parte importante da cultura pública, se encontra cada vez mais influenciada pela nova economia política. Nesta economia, como afirma Richard Sennett (2004, p. 147) "trabalho e local estão se transformando de determinadas formas que pareciam inimagináveis há meros vinte anos". É o caso da educação que além de universal tem se transformado também em um aspecto importante da economia global, na medida em que a concorrência no mercado mundial torna obrigatório o novo padrão de produtividade, configurado pelo casamento, sob regime mercantil, da investigação cientifica - que se espera seja crescentemente desenvolvida no espaço da universidade-, e o processo produtivo. O segundo é o de que, do ponto de vista global, para efeito de influências sobre a educação, o processo de globalização se realiza desigualmente entre os diversos sujeitos envolvidos com o seu processo. Isto é, a educação como fenômeno universal é de uma determinada configuração nos países desenvolvidos e outra diferente nos países subdesenvolvidos. Enquanto nos primeiros ela se mostra mais comprometida com a ponta do processo, qual seja: a produção de conhecimento novo, aqui, ou em, praticamente, todos os outros países subdesenvolvidos, a preocupação se dá sob a perspectiva operacional da difusão e propagação do progresso técnico ii .

Esse processo fomenta indubitavelmente um clima de perplexidade que perpassa a sociologia contemporânea, que se reflete diretamente no universo da educação e, especificamente, da educação escolar, tanto no sentido do aumento de suas incertezas como no de seus desafios. Para compreendê-lo, no entanto, o raciocínio tipo causa-efeito não se presta. Mesmo porque, talvez, não exista uma só causa que dê conta de explicar a situação. São muitas que podem ser aventadas, mas nenhuma com as propriedades da certeza e da universalidade.

A falta tanto de maiores certezas e/ou universalidade das possíveis causas que poderia estar atuando no mundo contemporâneo e, sobretudo, no mundo do porvir não impede, no entanto, que autores, mesmo com pontos de vista diferentes em relação a modernidade, tais como: Jean Boudrillard (1985), Alain Touraine (2006), Richard Sennett (2006), Leslie Sklair (2002), Manuel Castells (1999), José Gimeno Sacristán (2002), Francisco de Oliveira (2004) entre muitos outros, concordem em pelo menos um ponto básico, o de que o mundo que a sociologia se habituara a analisar nestes últimos dois ou três séculos, deixou, praticamente, de existir. Alguns como Baudillard (1983) ou mesmo Touraine (2006), com o seu novo paradigma da guerra infinita, deixam pouco espaço para se pensar a reversão das expectativas criadas no mundo com os recursos institucionais habituais que nos acostumamos a usar ao longo período moderno, que alguns mais apressados julgam ter encerrado seu ciclo na história da humanidade. Para os citados autores, mais especialmente para Baudrillard, a modernidade de tantas revoluções e transformações, desde os campos da economia, da sociedade, da cultura e, sobretudo da ciência, se encontra atualmente em uma encruzilhada e o que é pior, sem saída boa. Segundo idéias do autor temos, de um lado, a "sombra das maiorias silenciosas" e de outro, o fim do social e o surgimento das massas magnetizadas pelos novos controles midiáticos manipulados "por uma espécie de eletricidade estática". Deste modo, a perda do sentido social e a decadência do político são conseqüências inevitáveis que dificilmente poderão ser evitadas, principalmente se tentadas a partir do quadro de análise e categorias que nos 
acostumamos a usar ao longo deste período. Quase na mesma linha, mas divergindo pelo menos quanto ao epitáfio da modernidade, Touraine sinaliza em suas análises praticamente a mesma senha de decomposição do social. Sem meias palavras, o autor nos chama a atenção para o fato da sociedade contemporânea estar atravessando um caminho, que para ele é sem volta, que é o da decadência acelerada do paradigma do social. Paradigma este, de profunda importância para a modernidade, dado que foi em torno dele que toda modernidade se estruturou. Diante deste fato estaríamos, segundo suas intrigantes idéias, assistindo a passagem da lógica da sociedade, que outrora sucedera a lógica da política, para uma nova lógica, totalmente distinta, materializada no processo de globalização, realizados sem qualquer controle ou regulação social e política. Uma lógica de campo aberto para fazer a guerra dos mercados.

Estas considerações nos permitem, por sua vez, inferir que tanto em uma como em outra das análises a educação estaria deixando de ser reconhecida prioritariamente pela hegemonia que exercera ao longo de toda a modernidade, como agência de socialização. Ao que tudo indica, esta hegemonia estaria sucumbido a favor de outras estruturas de controle social mais compatível com as exigências impostas pelo acirramento do processo de globalização do capitalismo. Não se trata mais de uma dominação que se exerça individualmente pela socialização das pessoas pela via de uma única agência, de forma planejada e sistemática, como é o caso da escola, mas sim, por um sistema de massas, capaz de perfazer a dominação não mais como uma submissão do explorado pelo explorador, como se fazia antigamente nos períodos do capitalismo concorrencial e monopolista, mas ironicamente pela reivindicação do próprio explorado para que o aparato sob o qual ele se encontra submetido e explorado, de maneira certamente mais intensa, seja ampliado ainda mais. Já em meados da década de 50 do século passado, Marcuse chamava atenção para um fenômeno peculiar, "o de que a dominação nas sociedades capitalistas industrialmente desenvolvidas tende a perder o seu caráter explorador e opressivo e a tornar-se "racional", sem que com isso a dominação política desapareça: a dominação só continua a depender da capacidade e do interesse de manter e ampliar o aparato como um todo" (MARCUSE apud HABERMAS, 1983, p.314).

Neste caso, a escola continuaria a fazer parte do sistema de dominação, mas não mais como uma força hegemônica e sim como apenas uma das forças que formam o aparato técnico-científico através do qual o sistema de dominação se legitima e se reproduz. Entretanto, é impossível se discutir os temas da ciência, da tecnologia se não se considerar duas questões fundamentais. A primeira assinala que apesar de ciência, tecnologia e educação serem campos distintos, elas são também complementares e, sobretudo indissociáveis. A segunda pondera a incorreção de limitar o processo de globalização ao âmbito estritamente econômico.

Em outras palavras, a necessidade de pensarmos os temas da ciência, da tecnologia e da educação conjunta e complementarmente implica pensarmos a globalização como um processo integrado, que não se limita de forma alguma, ao âmbito estrito da economia. A expansão das relações capitalistas mundiais de produção é forte evidência desta afirmação. Não se trata apenas de um processo econômico, mas também da cultura, na medida em que ciência e tecnologia, grandes representações da cultura moderna, representam o núcleo e a alma da globalização econômica. Assim como é impensável, nos padrões de concorrência estabelecidos mundialmente, se fazer qualquer proposta de desenvolvimento capitalista independentemente da ciência e da tecnologia, não se pode pensar a absorção da ciência e da tecnologia desvinculadas da cultura para a qual e nas qual foram inicialmente imaginados. 
Esse entendimento é importante não só porque permite a compreensão da importância estratégica da ciência e da tecnologia no processo de globalização, mas também para a compreensão da lógica que preside o processo de internacionalização da educação.

Herbert Marcuse, em um contexto bastante diferente já apontava para a relação ciência-tenologia e poder, quando se referia à simbiose entre o capital produtivo e o progresso técnico-científico, como uma nova forma inconfessada de dominação política nas sociedades contemporâneas.

Para chegar a esta conclusão, Marcuse parte da hipótese do conceito de razão técnica já se constituir desde o início do processo produtivo capitalista como uma nova ideologia. Marcuse afirma: Não apenas a sua aplicação, mas já a própria técnica é dominação (sobre a natureza e sobre o homem), dominação metódica, científica, calculada e calculadora. Continua Marcuse, não é apenas de maneira acessória, a partir do exterior que são impostas à técnica fins e interesses determinados - eles já intervêm na própria construção do aparato técnico; a técnica é sempre um projeto (PROJECT) histórico-social, nela é projetado (PROJEKTIERT) aquilo que a sociedade e os interesses que a dominam tencionam fazer com o homem e as coisas. Tal objetivo de dominação é imaterial e, nessa medida, pertence à própria forma de razão técnica (MARCUSE apud HABERMAS, 1982, p.304).

No mesmo texto, mais a frente, Habermas nos informa que Marcuse completa o raciocínio afirmando:

Os princípios da ciência moderna foram estruturados a priori de modo a poder servir de instrumentos conceituais para um universo de controle produtivo que se perfaz automaticamente; o operacionalismo teórico passou a corresponder ao operacionalismo prático. O método científico que levou à dominação cada vez mais eficaz da natureza passou assim a fornecer tanto os conceitos puros, como os instrumentos para a dominação cada vez mais eficaz do homem pelo homem através da dominação da natureza (...) Hoje a dominação se perpetua e se estende não apenas através da tecnologia, mas enquanto tecnologia e esta garante a formidável legitimação do poder político em expansão que absorve todas as esferas da cultura (MARCUSE apud HABERMAS, 1982, p, $305)$.

Segundo, portanto, Marcuse, a intensificação do uso da razão técnica tende a transfigurar o problema da exploração do regime capitalista. E nisso consiste o fundamental do esforço de reengenharia da sociedade moderna, ou seja, dar a questão da dominação uma nova configuração. Uma configuração que seja ao mesmo tempo mais exploração no sentido do aumento da mais-valia e menos compreendida politicamente como exploração. Uma exploração que deixe de ser "irracional" e passe a ser entendida como "racional", na medida em que a sua constituição se identifica cada vez mais com o uso da racionalidade do aparato técnico-científico utilizado para desenvolver a produção. Com isso a nova dominação espera não só ampliar a sua dominação política e econômica sobre a sociedade, como introduzir a ciência e a tecnologia como um novo elemento de mediação entre ela e a sociedade. Trata-se, portanto de duas fases a cumprir: a primeira, diz respeito à construção de um aparato científico-tecnológico capaz de ser operado internacionalmente, e a segunda, de propagar e difundir esse aparato, o que implica fazê-lo reconhecido e manipulado em qualquer lugar do mundo. Quanto a primeira fase, o vertiginoso crescimento da tecnologia, concentrado exclusivamente nos poucos países 
desenvolvidos do mundo, nos últimos vinte a trinta anos, praticamente se completou, com a vantagem dele próprio se realimentar em movimento aparentemente infinito. Ou seja, quanto mais o aparato científico-tecnológico amplia sua diversidade de recursos mais cria condições para seu autodesenvolvimento. Quanto a segunda fase, caracterizada pelo objetivo da propagação do aparato científico-tecnológico, sua implantação está em franco desenvolvimento através das diferentes agências internacionais, tais como a UNESCO, com a sua agência regional para a América Latina e Caribe, a OREALC ${ }^{\mathrm{iii}}$; a CEPAL ${ }^{\mathrm{iv}}$, além do Banco Mundial. Em comum todas essas agências atuam no sentido da fomentação da educação como um dos mais importantes instrumentos de difusão e propagação do conhecimento científico-tecnológico entre os países da região.

Conforme registra a CEPAL-OREALC, no documento intitulado "Educación y Conocimiento":

En su propuesta titulada Transformación productiva con equidad ${ }^{\mathrm{v}}$, la Comisión Económica para América Latina y el Caribe (CEPAL) sostuvo una idea central, en torno a la cual se articularon las demás: la incorporación y difusión deliberada y sistemática del progreso técnico constituye el pivote de la transformación productiva y de su compatibilización con la democratización política y una creciente equidad social. [...] es el progreso técnico lo que permite la convergencia entre competitividad y sustentabilidad social, y, fundamentalmente, entre crecimiento económico y equidad social. (CEPAL - OREALC, 1990:15).

Segundo se pode deduzir da proposta da CEPAL e da OREALC a propagação do progresso técnico se constitui, por si mesmo, como uma das mais importantes estratégias para a América Latina vencer definitivamente suas dificuldades sociais, políticas e econômicas.

Celso Furtado tem-nos chamado constantemente à atenção para o entendimento do capitalismo como um processo de difusão do progresso técnico, difusão irregular, comandada pelos interesses das economias criadoras, de novas técnicas. (FURTADO, 1992, p.37). Além disso, Furtado insiste na tese de que a propagação do progresso técnico, o objetivo máximo da estratégia da CEPAL-OREALC para as reformas do ensino nos países de A. L. e Caribe, tem se constituído na grande responsável pela configuração do que chama sistema "centro-periferia". Sistema representativo da dependência dos países subdesenvolvidos aos desenvolvidos. Explicando com mais detalhes Furtado nos esclarece que essa ação se realiza na forma de processos produtivos mais eficazes e também do desenho de novos produtos que são a face exterior da civilização industrial.

Conclui em seguida afirmando que a propagação de novas técnicas, inerente a acumulação, é antes de tudo a difusão de uma civilização que instila nas populações padrões de comportamento em transformação permanente. Trata-se da difusão de valores que tendem a universalizar-se (FURTADO, 1992, p.40). Nesta medida o processo deve ser também entendido no seu caráter cultural.

Nesse contexto, os cursos de formação de professores, por exemplo, não podem desconhecer que a difusão do progresso técnico proposta nas reformas educacionais, praticamente em todos os países da região, pode não estar propagando o progresso como tal, como querem os seus defensores, mas sim, uma forma inconfessada de dominação política.

A educação no mundo atual configura-se no interior de uma política pública que é profundamente influenciada pela nova economia política, a economia da globalização. Deste ponto de vista o processo de globalização merece um espaço importante para a 
reflexão na medida em que muitas das desconstruções que se tem falado, e a escola é uma delas, tem suas origens vinculadas ao seu desenvolvimento. Sacristán (2003), que está longe de ser considerado um pensador pós-moderno, nos chama a atenção para cinco eixos sob os quais o processo de globalização estaria exercendo forte pressão com importantes consequiências para a área social da educação. Os grandes eixos da "arquitetura" da modernidade que, segundo as análises do autor, teriam sido fortemente abalados nas sociedades capitalistas contemporâneas são os seguintes: "1 - o papel do Estado; 2 - a estruturação da sociedade; 3 - o trabalho; 4 - a cultura; 5 - o sujeito" (SACRISTÁN, 2002, p. 60). Como se pode perceber, todos são eixos com projeções importantes para a educação: para a forma de concebê-la, para a forma de realizá-la e para a hierarquia dos valores que se avalia, devam servir ao cumprimento dos objetivos estabelecidos nas políticas educacionais.

Dos eixos assinalados por Sacristán (2002) delimitamos nosso interesse em abordar o Trabalho como categoria central na perspectiva de investigação da produção da sociabilidade na realidade em curso e como mediação para a problematização da educação escolar na perspectiva de formação dos indivíduos.

\section{A categoria Trabalho}

Consideramos que um possível ponto de partida para a análise do trabalho na atual forma de produção da existência humana requer a recorrência às contribuições de Lukács (1979) que examina o trabalho da perspectiva de prática social vital para a humanização do homem ressaltando que tudo aquilo que no trabalho e por meio do trabalho surge de expressamente humano constitui, precisamente, aquela esfera do humano sobre a qual direta ou indiretamente, baseiam-se todos os valores.

A produção de valores na sociedade contemporânea funda-se tendencial e predominantemente na relação Capital, Trabalho Assalariado e Propriedade Privada. Os limites e as possibilidades de perpetuação e/ou superação dessa relação constituem e tensionam o desenvolvimento objetivo de cada indivíduo em sua particularidade e genericidade, ou ainda, de cada indivíduo como ser particular e ser pertencente ao gênero humano. As ações singulares e coletivas que os indivíduos cotidianamente realizam expressam a especificidade histórica desse modo de produzir e reproduzir a vida social. Nesse contexto a prática social de cada ser particular, circunscreve-se a uma dupla e simultânea dependência e independência em relação: (a) à produção de valores de uso, que no capitalismo, representa, para o ser social trabalhador, a dupla servidão em relação ao objeto de trabalho (condição de existência) e à aquisição de valores de uso que sob a forma de mercadorias são vitais para sua sobrevivência, limitada pela transformação em mercadoria de sua capacidade de trabalho; (b) aos processos e relações estabelecidas para a produção de valores de uso (fato fundamental): organização, racionalização, distribuição, apropriação, dos quais é sujeito singular e pelos quais é coagido, explorado e alienado.

Nesse processo o trabalho constitui dimensão ontológica do ser social sobre a qual direta ou indiretamente, baseiam-se todos os valores. O trabalho é produtor de valores; agente singular e coletivo das mudanças ocorridas no processo de trabalho socialmente necessário; instigador do desenvolvimento das faculdades humanas; expressão dos carecimentos humanos; fundamento objetivo dos processos e embates valorativos das relações sociais. Em outras palavras, o trabalho, independente das formas sociais que o produziram ou produzirem, é ineliminável e, portanto, elemento central na estrutura constitutiva do ser social. 
O trabalho no atual estágio de desenvolvimento histórico transforma-se em fundante da prática social embora irredutível a esta, carregando consigo, nos processos de reprodução social, a natureza contraditória do capitalismo. E isto considerando que:

(...) a reprodução é a categoria determinante para o ser em geral: ser significa, em sentido estrito, se reproduzir. Do ponto de vista biológico os traços fundamentais e elementares da vida são nascer, viver e morrer, aos quais não têm analogia no ser inorgânico, mas são conseqüências diretas deste fato ontológico basilar. Ora, já que o ser social possui como sua própria base insuprimível o homem enquanto ser vivo, é manifesto que esta forma de reprodução também constitui um momento, igualmente insuprimível, da reprodução social. Mas só um momento, já que pela combinação da atividade social dos homens na reprodução da vida, que constitui sempre o fundamento de ser de todas as suas formas de cooperação, nascem categorias e relações categoriais completamente novas, qualitativamente diversas que (...) modificam também a reprodução biológica da vida humana (LUKÁCS, 1981, p. XIV).

A reprodução da vida na formação social capitalista constitui um devir histórico em que a racionalidade do movimento da totalidade social centra-se na mercantilização da vida em todas suas dimensões com base no trabalho social, quantitativo e abstrato e na tendência à diminuição do trabalho socialmente necessário e se possível à sua destruição. Aqui as práticas sociais reafirmam a ineliminável concomitância do homem singular e das circunstâncias sociais. $\mathrm{O}$ ato singular de produzir a vida e criar as condições de sua possível reprodução contém uma série de determinações sociais gerais e estas por sua vez se referenciam nos atos singulares. Desta perspectiva produção de valores, trabalho e reprodução social, são práticas sociais fundantes da vida cotidiana e constituem para cada indivíduo uma tensão real entre as alternativas que cria para sua constituição e o movimento da totalidade social. O indivíduo cria riquezas e empobrece; os valores de uso que diretamente produz, não lhe pertencem; foi reduzido a proprietário de sua capacidade de trabalho; para viver precisa formalizar a venda de sua capacidade produtiva ou se submeter ao trabalho informal, à mendicância ou transgredir a ordem estabelecida; negamlhe as condições de sobreviver minimamente em nome da oferta de oportunidades que segundo dizem, não soube aproveitar; exigem-lhe níveis de escolaridade que independem de sua atividade produtiva. Enfim, os exemplos poderiam se alastrar, mas avaliamos que são suficientes para afirmar que a lógica inerente ao Capital, em sua busca de subordinar o Trabalho, potencializa processos de alienação, desqualificação, desemprego estrutural, naturalização das relações sociais, dentre outros.

A avaliação de Lukács sobre a categoria trabalho, alinhada às concepções de Marx, expressa o caráter central desta categoria entendida como prática social fomentadora de valores de uso cuja realização contém um significado ontológico. Em outras palavras, o processo de trabalho realiza dupla transformação:

Por um lado, o próprio homem que trabalha é transformado pelo seu trabalho; ele atua sobre a natureza exterior e modifica, ao mesmo tempo, sua própria natureza, 'desenvolve as potências nela ocultas' e subordina as forças da natureza 'ao seu próprio poder'. Por outro lado, os objetos e as forças da natureza são transformados em meios, em objetos de trabalho, em matérias-primas, etc. $\mathrm{O}$ homem que trabalha 'utiliza as propriedades mecânicas, físicas e químicas das coisas, a fim de fazê-las atuar como meios para poder exercer seu poder sobre outras coisas, de 
acordo com sua finalidade'. Os objetos naturais, todavia, continuam a ser em si o que eram por natureza, na medida em que suas propriedades, relações, vínculos, etc., existem objetivamente, independentemente da consciência do homem; e tão-somente através de um conhecimento correto, através do trabalho, é que podem ser postos em movimento, podem ser convertidos em coisas úteis (Lukács, 1979, p. 16).

O movimento acima assinalado, do qual se podem depreender as contradições que realizam a dinâmica da totalidade social, bem como, o processo social de formação do indivíduo, se torna mais explícito nas palavras do próprio Marx.

É precisamente na acção sobre o mundo objectivo que o homem se manifesta como verdadeiro ser genérico. Tal produção é a sua vida genérica activa. Através dela, a natureza surge como sua obra e a sua realidade. Por conseguinte, o objecto do trabalho é objectivação da vida genérica do homem: ao não reproduzir-se apenas intelectualmente, como na consciência, mas activamente, ele duplica-se de modo real e intui o seu próprio reflexo num mundo por ele criado. Pelo que, na medida em que o trabalho alienado subtrai ao homem o objecto da sua produção, furta-lhe igualmente a sua vida genérica, a sua objectidade real como ser genérico (...) (Marx, 1989, p. 165-166).

Conforme Marx, a vida humana para se efetivar produziu a propriedade privada e agora precisa negá-la para reafirmar-se; desta forma, o horizonte de alternativas para as práticas sociais dos indivíduos é produzido predominantemente pela totalidade social, e traz em si a potência e contradição, da afirmação e negação da propriedade privada pela prática singular do homem. O homem produziu uma sociedade, por meio da realização da economia política, que ao mesmo tempo o afirma como sujeito, e ao incorporar, no "plano subjectivo", a lógica "objetiva e mecânica" da economia política, tende a negá-lo, no contexto do trabalho, da prática social e da reprodução social.

Deste modo é enunciada a categoria ontológica central do trabalho: através dele realiza-se, no âmbito do ser material uma posição teleológica que dá origem a uma nova objetividade. Assim, o trabalho se torna o modelo de toda práxis social, na qual, de todo modo - mesmo que através de mediações às vezes muito complexas - sempre são transformadas em realidade posições teleológicas, em termos que, em última análise, são materiais. É claro (...) que não se deve ser esquemático e exagerar este caráter paradigmático do trabalho em relação ao agir humano em sociedade; mas assim mesmo, ressalvadas as diferenças, que são muito importantes, veremos que há uma essencial afinidade ontológica e esta brota do fato de que o trabalho pode servir de modelo para compreender as outras posições sócio-teleológicas exatamente porque, quanto ao ser, ele é a forma originária (Lukács, 1981, p. 6, grifos nossos).

O trabalho de simples produtor de valor de uso nos estágios menos evoluídos da humanidade, transforma-se no estágio atual de desenvolvimento histórico em modelo da prática social, carregando consigo, nos processos de reprodução social a progressão contraditória do capitalismo. É, pois, segundo, Lukács, a protoforma do ser social em suas dimensões irrepetível e da totalidade social. 
De outra parte, a concepção lukacsiana de sociedade como complexo de complexos, remete aos grupos humanos e aos homens singulares como base da formação, mediação e diferenciação das relações sociais e do tensionamento das alternativas fundadas no processo de trabalho. Mas as preocupações teóricas de Lukács; alastram-se na direção de apontar e criticar a dupla deformação advinda das análises da prioridade ontológica da esfera econômica.

Um dos componentes dessa deformação recai, conforme Lukács, na naturalização da realidade econômica que emerge como processo sujeito a leis universais privadas da presença da ação consciente dos homens. O outro componente incide em dotar a suposta logicidade (legalidade) da esfera econômica de um mecanismo fatal que a tudo subordina e a todos determina.

Lukács endereça suas críticas às dicotomias filosóficas que se degladiam entre um ser determinado segundo leis, e, portanto, privado de consciência e uma consciência, essencialmente cognitiva, privada de ser. Dessa perspectiva consideramos necessário ressaltar que:

(...) segundo a concepção materialista de história, o fator que em última instância é determinante na história é a produção e a reprodução da vida real. Mais não foi afirmado, nem por Marx nem por mim. Se agora alguém deforma as coisas, afirmando que o fator econômico seria o único fator determinante, transforma aquela proposição numa frase vazia, abstrata, absurda (Engels apud Lukács, 1979, p.154, grifos nossos).

Lukács enfatiza a predominância da totalidade sobre os demais complexos sociais de sorte que a racionalidade do movimento do complexo total será a mesma para os demais complexos nas suas respectivas especificidades e realça que tal racionalidade reside no desenvolvimento das forças produtivas e no processo econômico. Como aprofundar esse suposto, quando analisamos o complexo social educação?

Entendida em seu significado mais amplo, a educação busca constituir o sujeito para o momento histórico em curso.

O caráter contraditoriamente humanizador e alienador com que a objetivação do ser do homem se realiza no interior das relações sociais de dominação, tem implicações importantes no que diz respeito à formação da individualidade. Por um lado a formação do indivíduo enquanto um ser humano não pode se realizar sem a apropriação das objetivações produzidas ao longo da história social, mas por outro lado, essa apropriação também é a forma pela qual se reproduz a alienação decorrente das relações sociais de dominação (Duarte, 2001, p.24).

Portanto, se o complexo de relações sociais é produzido por meio de práticas individuais, e nelas, a totalidade social se expressa, nessas práticas também se manifesta a contradição entre o ser humano e a negação social de tal condição. Consideramos que uma possível resposta ao aporte propiciado por uma abordagem ontológica da educação requer um suposto que contribuiria para pôr em debate o que se tem proposto para a educação nos seus mais diversos matizes e para a ampliação do entendimento que se tem das complexas relações entre trabalho e educação escolar com suas derivações nos processos de produção/apropriação de conhecimento, de institucionalização das práticas formativas e de intervenção no âmbito do cotidiano escolar. Avaliamos que as reformas educacionais em curso, promovem a redução do indivíduo às habilidades cognitivas de sua consciência e a 
supostas competências que articulam suas possíveis condições de adaptação à mercantilização da vida nos limites da educação para o trabalho (Capital) e para a cidadania (Estado)

$\mathrm{O}$ referido suposto incorpora duas dimensões. Uma procura alertar para a impossibilidade da ontologia somente no plano da consciência, insistindo na impossibilidade da existência tão somente no plano gnosiológico. Em outros termos, no âmbito das concepções lukascianas, a existência somente tem sentido na sua relação com a objetividade, e, essa, por sua vez, cada vez mais, por meio do trabalho e da prática social, torna-se objetivação. Nesse processo histórico o homem distancia-se da natureza, sem jamais poder suprimi-la. Do que se depreende, segundo Lukács, a impossibilidade do ser reduzido à consciência, ou, de uma ontologia resultante da unilateralidade abstrata, formal do trabalho filosófico. Para esse Autor, o trabalho e a prática social, na sua relação direta ou indireta com a natureza e a sociedade, são as únicas referências para uma ontologia do ser social em sua dimensão singular ou no âmbito da genericidade da espécie humana. Por outro lado, a existência do ser social jamais poderia completar-se sem a apreensão dos meios para a realização dos fins, o que implica afirmar a importância dos processos reflexivos e gnosiológicos, ainda que tais processos tenham como referência as formas de existência objetivas sociais ou naturais.

A outra dimensão sustenta-se no entendimento de que no ser humano, ainda que o biológico seja fundante e a dimensão social predominante, o social se volta sobre ele e o modifica. Por essa razão, o predominante na análise de um complexo social é o desenvolvimento contraditório da sociabilidade, sua tendência historicamente produzida. Assim, é preciso investigar a materialidade do processo de socialização, é necessário desvelar a dynamis do movimento social. Se tal busca reduzir-se somente às esferas sociais em si, sem relação com o complexo total, traduzir-se-á em uma análise que somente articula possíveis categorias de maneira lógica, sem apreender a racionalidade da totalidade social, que se encontra no seu momento predominante: a reprodução material da vida humana.

O desdobramento multifacetado desse processo produz a tensão real entre indivíduo e totalidade social e se expressa na possibilidade de sua passagem de ser em si a ser para si, ou ainda, parafraseando Agnes Heller, da sua passagem de ser homem inteiro para o ser inteiramente homem. A possibilidade dessa passagem do ser homem inteiro para o ser inteiramente homem, envolve o processo de formação do indivíduo aqui circunscrito à educação escolar. Com base nessas observações a questão aqui posta é se as práticas formativas no âmbito da instituição escolar fomentam a possibilidade de apropriação das objetivações genéricas do homem para-si. Dito de outra maneira, busca-se compreender se a ciência, a arte, a filosofia, a moral e a política são produzidas e mediadas por práticas formativas que objetivam remover radicalmente os processos de alienação e exploração constitutivos da razão de ser histórica da formação social capitalista.

Avaliamos que tais reflexões poderão fornecer elementos para ampliar o campo investigativo da formação humana na direção de situá-la como mediadora das esferas do trabalho e da educação escolar, bem como trazer elementos teóricos para melhor entendimento dos processos de individualização e socialização dos trabalhadores. E, sobretudo, contribuir para novas abordagens de pesquisa empírica sobre o tema da formação humana no âmbito da educação escolar.

\section{A categoria formação}

Revista HISTEDBR On-line, Campinas, $n$. Especial, p.198-215, mai.2009 - ISSN: 1676-2584 
As considerações aqui registradas sobre a categoria trabalho, alimentam uma questão vital derivada dos processos de formação do individuo produtor e produto da realidade social vigente: as práticas formativas no âmbito da instituição escolar fomentam a possibilidade de apropriação das objetivações da vida genérica do homem para-si? Dito de outra maneira, a ciência, a arte, a filosofia, a moral e a política são produzidas e mediadas por práticas formativas que objetivam remover radicalmente os processos de alienação e exploração da razão de ser histórica da formação social capitalista?

Uma possível resposta a essas indagações requer pressupor que nas formações sociais capitalistas as práticas formativas se desenvolvem contraditoriamente num processo de apropriação tensionado pela possibilidade de que cada indivíduo incorpore as objetivações historicamente produzidas nos limites de um processo fundado em relações sociais de dominação estruturada com base, reafirmamos, na mercantilização da vida em todas suas dimensões. Portanto, considera-se que a educação constitui uma prática social predominante no processo de produção/reprodução das relações sociais capitalistas. $\mathrm{O}$ trabalho educativo busca objetivar formas de agir e pensar voltadas para a formação do indivíduo e possibilitar - nos limites de suas contradições -, a apropriação do conhecimento historicamente produzido. Dessa perspectiva, investigar, analisar e problematizar, práticas formativas no contexto das Instituições Escolares, requer compreender se essas práticas representariam, predominante e tendencialmente, uma atividade utilitária, produtivista, ou se representariam a possibilidade de uma forma específica de práxis, constituída por suas indissociáveis dimensões, antropológica, histórica, gnosiológica e ontológica; conforme o aporte de Vázquez (1968).

Consideramos que o entendimento, a análise e a problematização da formação requer, no âmbito das práticas sociais, a busca dos supostos filosóficos, teóricos, ontológicos e ideológicos que referenciam os denominados processos formativos. Essa busca demanda esforços na perspectiva de um entendimento da formação humana no âmbito das práticas sociais derivadas da formação social capitalista, que busca romper os limites do tratamento lógico-gnosiológico que permeia diversas concepções teóricas presentes na esfera da reprodução social e particularmente na esfera educacional.

Pensar os múltiplos determinantes da esfera educacional remete a caracterizar, minimamente, as Instituições Escolares, como espaços historicamente produzidos, com base em dois supostos. Um, considera que o entendimento da Instituição Escolar como instituição social, vincula-se à análise dos conflitos e antagonismos subjacentes às práticas sociais centradas na relação Capital - Trabalho Assalariado - Propriedade Privada. E objetivada nas múltiplas mediações entre Sociedade e Estado; entendimento articulado, portanto, à investigação da objetividade social posta historicamente no contexto das formas e dos tempos da sociedade capitalista. O outro, infere que a Instituição Escolar materializa cotidianamente - por meio de processos de pesquisa e/ou ensino e/ou extensão, em suma, das políticas educacionais e da produção específica da cultura escolar - práticas formativas constitutivas das múltiplas dimensões de reprodução social do indivíduo.

Trata-se propositivamente de apreender o processo de objetivação da Instituição Escolar, considerando que em seus espaços e tempos históricos, legitimam-se e naturalizam-se as desigualdades sociais e em contrapartida se concretizam, ainda que parcialmente, as possibilidades de apropriação, compreensão e crítica das raízes históricas dessa legitimação e naturalização das relações fundantes da formação social capitalista, na perspectiva de sua superação.

Pondera-se que um dos objetivos da escola, seria o da socialização do conhecimento produzido pela humanidade, conhecimento entendido como saber. Dessa perspectiva, pensar o espaço escolar como espaço de apropriação dos saberes 
historicamente produzidos sobre o mundo dos objetos, requer reconhecer no mundo dos objetos processos de objetivação na perspectiva de satisfazer as necessidades humanas em suas múltiplas dimensões. E este reconhecimento pode assumir como suposto que o mundo dos objetos é imediato e naturalmente dado em conformidade com sua utilidade ou, apontar na direção de buscar o entendimento desse mundo como atividade fundada na práxis, originariamente humana, representada pelo Trabalho.

Enveredar sob o suposto do mundo dos objetos como natural, imediato e útil, representa um itinerário que, em última análise, nos aproxima do pragmatismo. Isto pode impossibilitar a articulação das mediações entre o mundo dos objetos e a origem e os desdobramentos históricos inerentes à sua produção. A tendência fomentada por essa perspectiva é a de se ater à expressão fenomênica dos fatos, o que colocaria a utilidade como o eixo central dos critérios que orientariam e subsumiriam as práticas formativas no espaço escolar, ao mundo prático, eficiente e utilitário. Em seus desdobramentos qual seria o critério de verdade sobre os saberes produzidos em relação ao mundo dos objetos? E de que maneira esse critério incidiria na formação do indivíduo?

/.../ Enquanto para o marxismo a utilidade é consequiência da verdade, e não seu fundamento ou essência, para o pragmatismo a verdade fica subordinada à utilidade, entendida esta como eficácia ou êxito da ação do homem, concebida esta última, por sua vez, como ação subjetiva, individual, e não como atividade material, objetiva, transformadora.

A diferença entre o marxismo e o pragmatismo no que concerne ao modo de conceber a verdade determina, por sua vez, seus diferentes critérios de verdade. Enquanto o primeiro procura provar o verdadeiro como reprodução espiritual da realidade, o segundo pretende provar $\mathrm{o}$ verdadeiro como o útil. Onde encontrar o critério da verdade? Há uma aparente coincidência quando um e outro respondem: na prática. Mas essa aparência coincidente se desfaz de imediato se levarmos em conta que o pragmatismo e o marxismo dão um significado muito diferente à prática: num caso, a ação subjetiva do indivíduo destinada a satisfazer seus interesses; no outro, ação material, objetiva, transformadora, que corresponde a interesses sociais e que, considerada do ponto-de-vista histórico-social, não é apenas produção de uma realidade material, mas sim criação e desenvolvimento incessantes da realidade humana (VÁZQUEZ, 1968, p.213).

Disso poder-se-ia depreender, no caso da prática escolar, que a cotidianidade é o lugar do predomínio do pragmatismo e do cognitivismo, em lugar do gnosiológico articulado com a história? E mais, a instituição escolar deveria ser um espaço de tensionamento e problematização da cotidianidade enraizada no mundo dos objetos utilitários?

Responder, ainda que precariamente, a estas indagações requer expor possíveis mediações entre a educação, o cotidiano escolar e as práticas formativas assumido a concepção de trabalho educativo formulada por Saviani e incorporada por Duarte, em sua abordagem das mediações entre educação escolar e cotidiano.

O trabalho educativo é o ato de produzir, direta e indiretamente, em cada indivíduo singular, a humanidade que é produzida histórica e coletivamente pelo conjunto dos homens. Assim, o objeto da educação diz respeito, de um lado, à identificação dos elementos culturais que precisam ser assimilados pelos indivíduos da espécie humana para que 
eles se tornem humanos e, de outro lado e concomitantemente à descoberta de formas mais adequadas de atingir esse objetivo (SAVIANI apud DUARTE, 2001, p. 43).

A perspectiva de compreender a educação como um processo mediador entre a vida do indivíduo e da sociedade e a concepção de trabalho educativo caracterizada como prática mediadora entre o ser indivíduo singular e sua humanização, requerem outra mediação centrada numa concepção de formação do indivíduo. Pois,

(...) sendo a educação um processo mediador entre a vida do indivíduo e a sociedade (e, portanto, a história), não nos parece possível analisar crítica e historicamente o processo pedagógico sem a mediação de uma teoria na qual a formação do indivíduo seja concebida enquanto um processo essencialmente histórico e social (DUARTE, 2001, p.20).

A mediação de uma teoria que referencie o processo de formação do indivíduo, repõe a possibilidade de uma formação centrada na prática imediata, utilitária e produtiva ou na práxis enraizada nos processos de objetivação e apropriação das múltiplas determinações da realidade social produzida e reproduzida no âmbito do cotidiano escolar. Assinale-se, conforme DUARTE (2001: p.38), que “(...) o desenvolvimento do indivíduo não se efetiva plenamente se sua vida reduzir-se à esfera do cotidiano. Quando isso acontece (redução da vida do indivíduo à esfera cotidiana) é porque a própria relação do indivíduo com o cotidiano é uma relação alienada". E acrescenta o Autor em pauta que uma dessas formas pelas quais a vida cotidiana reduz as possibilidades de desenvolvimento da individualidade humana, é "/.../ quando os processos de apropriação e objetivação se reduzem, para o indivíduo, ao nível da genericidade em-si, ao nível de sua reprodução espontânea enquanto alguém que ocupa uma determinada posição no interior da divisão social do trabalho" (idem). Diante do exposto, afirmaríamos que os processos de apropriação e objetivação, mediados pela educação escolar, representam práticas formativas que concebem, tendencial e predominantemente, o indivíduo em sua genericidade em-si.

\section{Buscando concluir}

Assinalamos que o percurso aqui registrado mereceria um tratamento mais criterioso que examinasse, dentre outros aspectos, as transformações no campo das Ciências Sociais e, particularmente, no campo educacional, decorrente da progressiva e intensiva subordinação da Ciência à lógica do Capital. Aqui possivelmente nos defrontaríamos com a predominância da fenomenologia e do estruturalismo em suas múltiplas versões fomentadoras do presentismo, do relativismo e da impossibilidade de apropriação objetiva da contraditoriedade produzida com base na sociabilidade em curso.

De outra parte, a observância das transformações no mundo do trabalho seria indicativa do deslocamento de processos formativos da classe trabalhadora mediados, no âmbito da educação escolar, por competências e habilidades articuladas à lógica da empregabilidade.

Diante do exposto, destacamos que o processo reformista passado e presente tende a se articular em períodos históricos em que o capital demanda a formação de um ser social que potencialmente atenda às metamorfoses de suas possibilidades de produção, circulação, distribuição, consumo, concentração e apropriação da riqueza socialmente produzida. Nesse contexto de crise e tensões sociais, as reformas educacionais buscam 
acentuar e ajustar os processos de internalização dos valores intrínsecos às transformações do Capital em suas múltiplas dimensões. A política educacional no contexto da reforma do Estado promovida pelos setores dominantes da sociedade brasileira nos anos noventa do Século passado, nucleada na denominada educação para o trabalho e para a cidadania, referencia-se em práticas formativas voltadas para a formação do indivíduo nos limites do mundo prático, utilitário, imediato, eficaz e eficiente. Isto é, produzindo um processo formativo centrado no indivíduo e na sua adaptação à realidade em que vive na perspectiva da naturalização e da permanência das formações sociais capitalistas.

Avaliamos que esses aspectos essenciais para a problematização e busca de alternativas norteadoras da produção de um campo investigativo referenciado nas categorias Trabalho e Formação e tensionado pelo denominado processo de globalização mereceriam cuidados que fogem aos propósitos deste escrito. Entretanto, essas insuficiências não impedem a formulação de seguinte problema:

O educador deve criar alternativas que reafirmam a produção de relações de dominação e alienação humana ou assumir como alternativa o tensionamento de práticas formativas centradas na construção de relações enraizadas nas possibilidades da emancipação humana?

\section{Referências Bibliográficas}

BAUMAN, Zygmunt. Globalização: as conseqüências humanas. Rio de Janeiro / RJ: Jorge Zahar Editor, RJ, 1999.

CEPAL-OREALC - Educación y conocimiento. Santiago de Chile: Naciones Unidas, 1992.

DUARTE, Newton. Educação escolar, teoria do cotidiano e a escola de Vigotski. Campinas, SP: Autores Associados, 2001, 3 a ed.

FURTADO, Celso. Brasil: a construção interrompida. Rio de Janeiro: Paz e Terra, 1992.

HABERMAS, Jürgen. Técnica e ciência como ideología. In: Os Pensadores XLVII, $1^{\text {a }}$ ed., 1975.

LUKÁCS, Gyorgi. Ontologia do ser social - os princípios ontológicos fundamentais de Marx. São Paulo: Ciências Humanas, 1979.

LUKÁCS, György. A Reprodução. In: Per uma ontologia dell'essere sociale. Roma: Reuniti, 1981, Tradução de Sérgio Lessa, Unicamp, S.P.

MARX, Karl. Manuscritos econômicos-filosóficos. Lisboa: Edições 70, 1989.

O Capital. Rio de Janeiro: Civilização Brasileira, 1982.

SACRISTÁN, Gimeno. Educar e conviver na cultura global: as exigências da cidadania. Porto Alegre: Artmed, 2002.

Revista HISTEDBR On-line, Campinas, n. Especial, p.198-215, mai.2009 - ISSN: 1676-2584 
SENETT, Richard. A cultura do novo capitalismo e a democracia. In: Combates e Utopias. Denis de Moraes (org) Guanabara, Rio de Janeiro: Record, 2004

VÁZQUEZ, Adolfo Sanchez. Filosofia da práxis. Rio de Janeiro: Civilização Brasileira, 1968.

\footnotetext{
${ }^{\text {i }}$ Professores do Programa de Mestrado e Doutorado em Educação da Universidade de Sorocaba (UNISO); Pesquisadores do Núcleo de Investigação do Trabalho Docente (NITDO - UNISO) vinculado à Rede de Estudos do Trabalho (RET).

ii Para maiores detalhes consultar o livro: Educación y conocimiento eje de la transformación productiva con equidad. Santiago, Chile: Naciones Unidas, CEPAL. Transformación productiva con equidad. Santiago, Chile: 1990.

iii Oficina regional de educación para América Latina y el Caribe - OREALC.

${ }^{\text {iv }}$ Comisión económica para América Latina y el Caribe - CEPAL

${ }^{\vee}$ CEPAL - Transformación productiva con equidad. La tarea prioritaria Del desarrollo de América Latina y el Caribe en los años noventa. Santiago de Chile: Naciones Unidas, 1990.
}

Artigo recebido em: 10/12/2008

Aprovado para publicação em: 15/01/2009 